\title{
ANALISIS KETIMPANGAN DISTRIBUSI PENDAPATAN PETANI BAWANG MERAH DAN NON PETANI BAWANG MERAH DI DESA LAM MANYANG KECAMATAN PEUKAN BADA KABUPATEN ACEH BESAR (Analysis of Farmers' Income Distribution Inequality Red Onions and Shallots Non Farmers in the Village of Lam Manyang Peukan Bada Subdistrict of Aceh Besar District)
}

\author{
Medita Ivanni ${ }^{1}$, T. Makmur ${ }^{1}$, Safrida $^{1}{ }^{*}$ \\ ${ }^{1}$ Program Studi Agribisnis, Fakultas Pertanian, Universitas Syiah Kuala
}

\begin{abstract}
Abstrak - Masalah ketimpangan pendapatan telah lama menjadi persoalan pelik dalam pelaksanaan pembangunan ekonomi yang dilaksanakan oleh sejumlah negara miskin dan berkembang. Penelitian ini bertujuan menganalisis tingkat ketimpangan distribusi pendapatan yang terjadi pada petani bawang merah dan non petani bawang merah di Desa Lam Manyang Kecamatan Peukan Bada Kabupaten Aceh Besar. Pengambilan sampel jenis mata pencaharian petani bawang merah menggunakan metode simple random sampling, sebanyak $20 \%$ dan sampel mata pencaharian non petani bawang merah menggunakan metode cluster random sampling, sebanyak $20 \%$. Metode analisis yang digunakan dalam penelitian ini adalah metode kuantitatif dengan menggunakan analisis pendapatan, analisis gini ratio, dan analisis dengan menggunakan kriteria bank dunia. Hasil penelitian diketahui bahwa analisis gini ratio menyimpulkan di Desa Lam Manyang mempunyai ketimpangan distribusi sedang, berbeda dengan menggunakan kriteria bank dunia di Desa Lam Manyang mempunyai ketimpangan distribusi rendah atau merata.
\end{abstract}

Kata Kunci : Ketimpangan Distribusi, Rumah Tangga dan Petani Bawang Merah

\begin{abstract}
The problem of income inequality farmers have become complicated problems in the implementation of economic development implemented by a number of poor and developing countries. This study aimed to analyze the level of inequality of income distribution that occurs in onion farmers and non farmers onion in the village of Lam Manyang Peukan Bada subdistrict of Aceh Besar district. Sampling livelihood onion farmers using sample random sampling method as much as $20 \%$ and sample livelihoods non onion farmers using cluster random sampling method as much as $20 \%$. The analytical method used in this research are quantitative method by using analysis of income, the Gini ratio analysis and analysis using World Bank criteria. The survey results revealed that the Gini ratio analysis concluded in the village of Lam Manyang have moderate inequality, as opposed to using the criteria of the world bank in the village of Lam Manyang have unequal distribution of low or uneven.
\end{abstract}

Keywords: Inequality Of Distribution, Households And Onion Farmer. 


\section{PENDAHULUAN}

Masalah distribusi pendapatan mengandung dua aspek. Aspek pertama adalah bagaimana menaikkan tingkat kesejahteraan masyarakat yang masih berada di bawah garis kemiskinan, sedangkan aspek kedua adalah pemerataan pendapatan secara menyeluruh dalam arti mempersempit perbedaan tingkat pendapatan antar penduduk atau rumah tangga. Keberhasilan mengatasi aspek yang pertama dapat dilihat dari penurunan persentase penduduk yang masih berada di bawah garis kemiskinan. Sementara keberhasilan memperbaiki distribusi pendapatan secara menyeluruh adalah jika laju pertambahan pendapatan golongan miskin lebih besar dari laju pertambahan pendapatan golongan kaya (Arsyad, 1997).

Aceh merupakan provinsi yang memiliki tingkat kesejahteraan masyarakat kurang sejahtera atas atau kata lain tingkat kesejahteraan rakyat provinsi Aceh berada pada kategori sejahtera bawah dan berada di urutan 21 dari 33 provinsi di Indonesia dan sekarang, jika dikaitkan dengan tingkat kemiskinan di Aceh. Menurut Kepala BPS Aceh (2015), penduduk miskin di provinsi Aceh pada Maret 2015 mencapai 851.586 orang dengan sebaran 157.000 orang berada di perkotaan dan 694.000 orang di perdesaan. Jumlah penduduk miskin di Aceh naik dari 16,98 persen ke 17,08 persen dari populasi penduduk Aceh saat ini.

Pada awalnya masyarakat di Desa Lam Manyang umumnya hidup sebagai nelayan, bertanam padi dan sebagian berkebun. Dalam kurun waktu terakhir ini, masyarakat di Desa Lam Manyang mulai membudidayakan tanaman bawang merah yang sekarang ini menjadi komiditi unggulan pada saat sekarang serta mendatangkan pendapatan yang maksimal. Masyarakat lainnya mulai tertarik pada tanaman bawang merah sebagai alternatif, hingga saat ini ada lebih ratusan warga yang mulai menjadikan kebun-kebun dan lahan kosong mereka untuk ditanami bawang merah. Sebagian besar masyarakatnya dapat dikatakan sebagai petani bawang merah, dan tau bagaimana cara menanam bawang merah. Hampir setiap minggunya masyarakat Desa Lam Manyang mengikuti pelatihan tentang budidaya tanaman bawang merah.

Menurut petani bawang merah yang berada di Desa Lam Manyang, kendala yang dihadapi petani saat ini adalah ketidakpastian harga, dan maraknya bawang impor. Jika harga pasar stabil para petani akan meraih untung yang menjanjikan, dikarenakan masa panen bawang merah hanya membutuhkan waktu 2 bulan. Kurangnya lahan dan pendapatan yang rendah berpengaruh terhadap kehidupan petani. Rata - rata pendapatan petani di Desa Lam Manyang sebesar Rp 500.000/bulan hingga Rp 1.000.000/bulan , jika dikaitkan dengan besarnya UMP Aceh 2016 yaitu sebesar Rp 2.100.000/bulan dapat dikatakan perekonomian petani bawang merah di Desa Lam Manyang masih tergolong rendah.

Dengan hal ini dapat dilihat bahwa terjadi ketimpangan yang terjadi pada tingkat pendapatan, sehingga perlu dilihat sejauh mana tingkat ketimpangan pendapatan petani bawang merah dengan masyarakat di Desa Lam Manyang

Analisis Ketimpangan Distribusi Pendapatan Petani Bawang Merah Dan Non Petani Bawang 156 Merah Di Desa Lam Manyang Kecamatan Peukan Bada Kabupaten Aceh (Medita Ivanni, Safrida, T. Makmur)

Jurnal Ilmiah Mahasiswa Pertanian Unsyiah, Vol. 2, No. 1, Februari 2017: 155-162 


\section{METODE PENELITIAN}

Teknik dalam pengambilan sampel yaitu apabila populasi kurang dari 100 lebih baik diambil semua hingga penelitiannya merupakan penelitian populasi. Namun jika jumlah populasinya besar dapat diambil antara 10-15\% atau 20-55\% (Arikunto, 2010). Metode analisis dalam penelitian ini menggunakan metode kuantitatif dengan menggunakan analisis pendapatan, analisis gini ratio, dan analisis dengan menggunakan kriteria bank dunia. Jenis data yang dikumpulkan dalam penelitian ini adalah data primer dan data sekunder. Data primer diperoleh dari dua macam teknik pengumpulan data, yaitu kuisioner dan wawancara. Pengambilan sampel jenis mata pencaharian petani bawang merah menggunakan metode simple random sampling, sebanyak $20 \%$ menjadi sampel dengan pertimbangan bahwa pola mata pencahariannya homogen sedangkan pengambilan sampel mata pencaharian non petani bawang merah menggunakan metode cluster random sampling, sebanyak $20 \%$ dengan pertimbangan pola mata pencahariannya heterogen.

\section{HASIL DAN PEMBAHASAN}

Berdasarkan hasil analisis ketimpangan distribusi pendapatan rumah tangga petani bawang merah dan non petani bawang merah di Desa Lam Manyang Kecamatan Peukan Bada Kabupaten Aceh Besar diperoleh hasil Uji Gini Ratio sebagai berikut:

Tabel 1. Perhitungan Indeks Gini Ratio Gini Pendapatan Rumah Tangga Petani Bawang Merah Dan Non petani bawang merah Di Desa Lam Manyang Kecamatan Peukan Bada Kabupaten Aceh Besar

\begin{tabular}{|c|l|c|}
\hline No. & \multicolumn{1}{|c|}{ Sampel } & Indeks Gini \\
\hline 1. & Petani Bawang Merah & 0,42 \\
\hline 2. & Non petani bawang merah & 0,35 \\
\hline & Total Keseluruhan KK sampel & 0,39 \\
\hline
\end{tabular}

Sumber : Data Diolah (2016)

Pada tabel dapat dilihat jenis pekerjaan yaitu petani bawang merah dan non petani bawang merah. Hasil koefisien gini menunjukkan bahwa sampel petani bawang merah sebesar 0,42, angka ini menunjukkan bahwa petani bawang merah memiliki distribusi ketimpangan sedang, dikarenakan bila koefisien gini antara 0,35 - 0,50 maka ketimpangan sedang. Untuk non petani bawang merah menunjukkan indeks gini sebesar 0,35 , angka ini menunjukkan bahwa non petani bawang merah memiliki distribusi ketimpangan sedang dikarenakan bila koefisien Gini bekisar antara 0,35 - 0,50 maka 
ketimpangan sedang. Pada total keseluruhan sampel diperoleh indeks Gini sebesar 0,37, ini artinya pada Desa Lam Manyang Kecamatan Peukan Bada Kabupaten Aceh Besar mempunyai nilai ketimpangan distribusi pendapatan sedang, dikarenakan bila koefisien Gini bekisar antara 0,35 - 0,50 maka ketimpangan sedang.

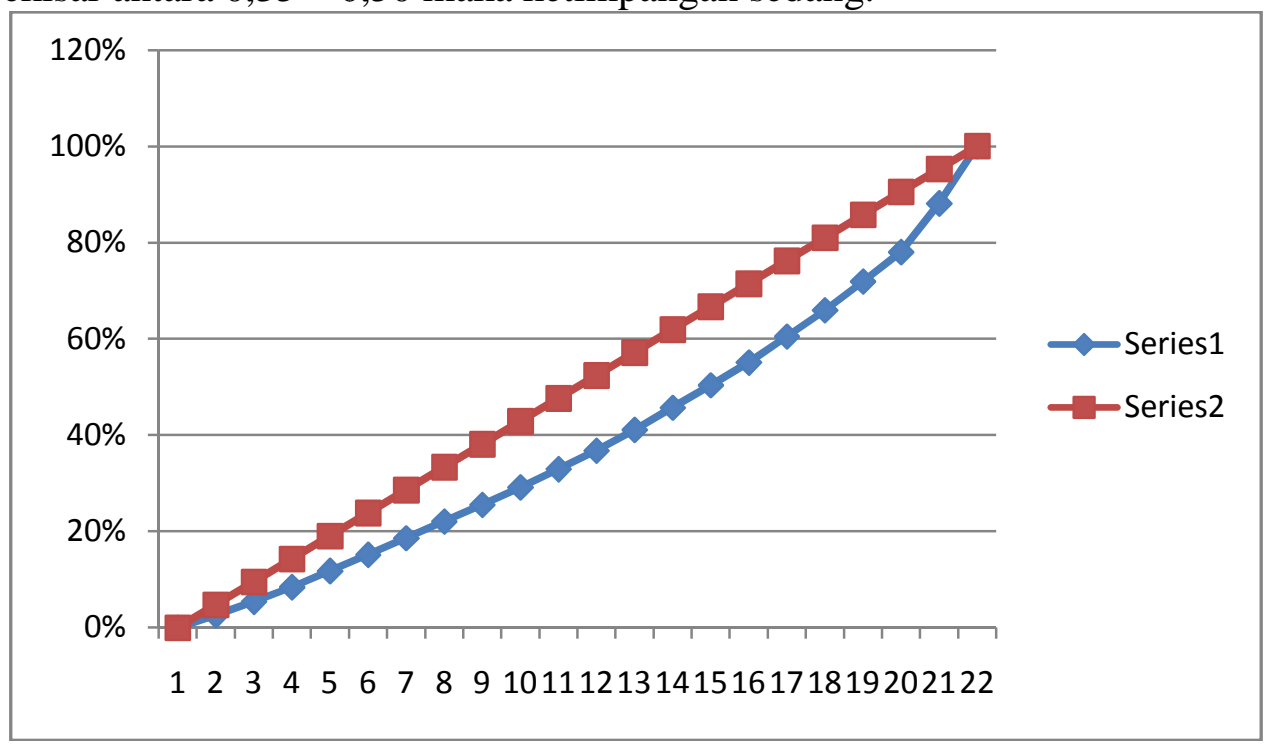

Gambar 1. Kurva Lorenz Total Keseluruhan KK Sampel di Desa Lam Manyang Kecamatan Peukan Bada Kabupaten Aceh Besar

Pada gambar, Kurva Lorenz dapat dilihat apabila semakin dekat pada garis pemerataan maka semakin merata pendapatan yang diperoleh total keseluruhan KK sampel, apabila semakin jauh dari garis pemerataan maka semakin timpang (tidak merata) pendapatan yang diperoleh penduduk. Maka dapat dilihat kurva untuk total keseluruhan KK sampel di Desa Lam Manyang Kecamatan Peukan Bada Kabupaten Aceh Besar kurvanya sedikit terlihat melengkung, ini artinya pendapatannya antara merata ataupun timpang, dan biasa disebut ketimpangan sedang.

\section{Analisis Dengan Menggunakan Kriteria Bank Dunia}

Analisis kriteria bank dunia mengelompokkan besarnya pendapatan dalam tiga kelompok yaitu :

- Apabila $40 \%$ penduduk pendapatan rendah menerima lebih kecil $12 \%$ dari jumlah pendapatan rendah atau ketimpangan tinggi.

- Apabila $40 \%$ penduduk pendapatan menerima antara $12 \%$ - $17 \%$ dari jumlah pendapatan sedang atau ketimpangan sedang.

- Apabila $40 \%$ penduduk pendapatan rendah menerima lebih besar $17 \%$ dari jumlah pendapatan cukup merata atau ketimpangan rendah.

Adapun klasifikasi distribusi pendapatan dan porsi pendapatan rumah tangga petani bawang merah berdasarkan Kriteria Bank Dunia adalah sebagai berikut :

Analisis Ketimpangan Distribusi Pendapatan Petani Bawang Merah Dan Non Petani Bawang 
Pada Tabel 2, berdasarkan Kriteria Bank Dunia dapat dilihat besarnya pendapatan pada kelompok rumah tangga petani bawang merah pada golongan $40 \%$ pendapatan rendah menerima pendapatan sebesar Rp 14.361 .768 ,- atau 32\% per bulan. Pada golongan $40 \%$ pendapatan sedang menerima pendapatan sebesar Rp 21.555.984,atau $47 \%$ per bulan. Pada golongan $20 \%$ pendapatan tinggi menerima pendapatan sebesar Rp 9.675.121,- atau 21\% per bulan. Ketimpangan distribusi pendapatan untuk petani bawang merah dikatakan rendah, dikarenakan pada $40 \%$ penduduk pendapatan rendah menerima lebih besar $17 \%$ pendapatan nasional.

Tabel 2. Klasifikasi Distribusi Dan Porsi Pendapatan Rumah Tangga Petani Bawang Merah Di Desa Lam Manyang

\begin{tabular}{|c|l|r|c|}
\hline No. & $\begin{array}{l}\text { Kelompok Rumah Tangga } \\
\text { (Kriteria Bank Dunia) }\end{array}$ & $\begin{array}{c}\text { Golongan Total } \\
\text { Pendapatan } \\
\text { (Rp/Bulan) }\end{array}$ & $\begin{array}{c}\text { Penerimaan Pendapatan } \\
(\%)\end{array}$ \\
\hline 1. & $40 \%$ pendapatan rendah & 14.361 .768 & 32 \\
\hline 2. & $40 \%$ pendapatan sedang & 21.555 .984 & 47 \\
\hline 3. & $20 \%$ pendapatan tinggi & 9.675 .121 & 21 \\
\hline & Jumlah & 45.592 .873 & 100 \\
\hline
\end{tabular}

Sumber : Data Diolah (2016)

Adapun klasifikasi distribusi dan porsi pendapatan rumah tangga non petani bawang merah berdasarkan Kriteria Bank Dunia adalah sebagai berikut:

Tabel 3. Klasifikasi Distribusi Dan Porsi Pendapatan Rumah Tangga Non Petani Bawang Merah Di Desa Lam Manyang

\begin{tabular}{|c|l|r|c|}
\hline No. & $\begin{array}{l}\text { Kelompok Rumah Tangga } \\
\text { (Kriteria Bank Dunia) }\end{array}$ & $\begin{array}{c}\text { Golongan Total } \\
\text { Pendapatan } \\
\text { (Rp/Bulan) }\end{array}$ & $\begin{array}{c}\text { Penerimaan } \\
\text { Pendapatan (\%) }\end{array}$ \\
\hline 1. & $40 \%$ pendapatan rendah & 8.835 .000 & 22 \\
\hline 2. & $40 \%$ pendapatan sedang & 12.779 .000 & 32 \\
\hline 3. & $20 \%$ pendapatan tinggi & 18.500 .000 & 46 \\
\hline & Jumlah & 40.114 .000 & 100 \\
\hline
\end{tabular}

Sumber : Data Diolah (2016)

Analisis Ketimpangan Distribusi Pendapatan Petani Bawang Merah Dan Non Petani Bawang

Merah Di Desa Lam Manyang Kecamatan Peukan Bada Kabupaten Aceh (Medita Ivanni, Safrida, 
Pada tabel, berdasarkan Kriteria Bank Dunia dapat dilihat besarnya pendapatan pada kelompok rumah tangga non petani bawang merah pada golongan $40 \%$ pendapatan rendah menerima pendapatan sebesar $\mathrm{Rp} 8.835 .000$,- atau $22 \%$ per bulan. Pada golongan $40 \%$ pendapatan sedang menerima pendapatan sebesar Rp 12.779.000,- atau $32 \%$ per bulan. Pada golongan $20 \%$ pendapatan tinggi menerima pendapatan sebesar Rp 18.500.000,- atau $46 \%$ per bulan. Ketimpangan distribusi pendapatan untuk non petani bawang merah dikatakan rendah, dikarenakan pada $40 \%$ penduduk pendapatan rendah menerima lebih besar $17 \%$ pendapatan nasional.

Adapun klasifikasi distribusi dan porsi pendapatan rumah tangga secara keseluruhan di Desa Lam Manyang sesuai Kriteria Bank Dunia adalah sebagai berikut:

Tabel 4. Klasifikasi Distribusi Dan Porsi Pendapatan Petani Bawang Merah dan Non Petani Bawang Merah Di Desa Lam Manyang Kecamatan Peukan Bada Kabupaten Aceh Besar

\begin{tabular}{|c|l|r|c|}
\hline No. & $\begin{array}{l}\text { Kelompok Rumah Tangga } \\
\text { (Kriteria Bank Dunia) }\end{array}$ & $\begin{array}{c}\text { Golongan Total } \\
\text { Pendapatan } \\
\text { (Rp/Bulan) }\end{array}$ & $\begin{array}{c}\text { Penerimaan } \\
\text { Pendapatan }(\%)\end{array}$ \\
\hline 1. & $40 \%$ pendapatan rendah & 23.082 .010 & 27 \\
\hline 2. & $40 \%$ pendapatan sedang & 33.962 .834 & 40 \\
\hline 3. & $20 \%$ pendapatan tinggi & 28.662 .029 & 33 \\
\hline & Jumlah & 85.706 .873 & 100 \\
\hline
\end{tabular}

Sumber : Data Diolah (2016)

Pada tabel, berdasarkan Kriteria Bank Dunia dapat dilihat besarnya pendapatan pada kelompok rumah tangga di Desa Lam Manyang pada golongan $40 \%$ pendapatan rendah menerima pendapatan sebesar Rp 23.082.010,- atau $27 \%$ per bulan. Pada golongan $40 \%$ pendapatan sedang menerima pendapatan sebesar Rp 33.962.834,- atau $40 \%$ per bulan. Pada golongan $20 \%$ pendapatan tinggi menerima pendapatan sebesar Rp $28.662 .029,-$ atau $33 \%$ per bulan.

Maka dapat disimpulkan bahwa ketimpangan distribusi pendapatan untuk petani bawang merah dan non petani bawang merah di Desa Lam Manyang dikatakan rendah, dikarenakan pada $40 \%$ penduduk pendapatan rendah menerima lebih besar $17 \%$ pendapatan nasional, yaitu sebesar $27 \%$.

\section{KESIMPULAN DAN SARAN}

Ada perbedaan dari hasil analisis yang digunakan yaitu menggunakan gini ratio dan kriteria bank dunia. Dimana gini ratio disimpulkan bahwa di Desa Lam Manyang 
mempunyai ketimpangan distribusi sedang sedangkan dengan menggunakan kriteria bank dunia di Desa Lam Manyang mempunyai ketimpangan distribusi rendah atau merata. Dari kedua analasis terlihat berbeda akan tetapi yang lebih akurat adalah dengan menggunakan analisis gini ratio, karena menggunakan analisis pendapatan mikro dan gini ratio merupakan analisis yang fluktuatif dalam mengukur ketimpangan distribusi. Sedangkan kriteria bank dunia menggunakan standar baku yang tidak diperbaharui.

Diharapkan kepada petani bawang merah di Desa Lam Manyang agar lebih memperhatikan pemeliharaan tanaman bawang merah dan juga disarankan untuk seluruh rumah tangga di Desa Lam Manyang agar memanfaatkan sumber-sumber daya lain yang menghasilkan pendapatan sampingan, untuk menunjang kebutuhan hidupnya sehari-hari.

\section{DAFTAR PUSTAKA}

Arikunto, S. 2010. Prosedur Penelitian Suatu Pendekatan Praktik. Rineka Cipta. Jakarta.

Arsyad, L. 1997. Ekonomi Mikro. BPFE. Yogyakarta.

Badan Pusat Statistik. 2015. Peukan Bada Dalam Angka 2015. Aceh.

Hasrimi, M. 2010. Analisis Pendapatan Petani Miskin dan Implikasi Kebijakan Pengentasannya di Kecamatan Perbaungan, Kabupaten Serdang Bedagai. Tesis Magister Sains. Sekolah Pascasarjana, Universitas Sumatera Utara. Medan

Lubis, A.H. 2010. Distribusi Pendapatan dan Tingkat Kemiskinan Petani Kopi Arabika di Desa Tanjung Beringin, Kecamatan Sumbul, Kabupaten Dairi. Jurnal Social Economic Of Agriculture And Agribusiness. Vol. 1 No. 1 (2012).

Makmur, T. 2011. Ketimpangan Distribusi Pendapatan Rumah Tangga Masyarakat Desa Kecamatan Peukan Bada Kabupaten Aceh Besar. Jurnal Agrisep. Vol. 12 No. 1 (2011).

Putra, L. D. 2011. Analisis Pengaruh Ketimpangan Distribusi Pendapatan Terhadap Jumlah Penduduk Miskin Di Provinsi Jawa Tengah Periode 2000 - 2007. Undergraduate thesis, Universitas Diponegoro.

Remi, S.S. dan P. Tjiptoherijanto. 2002. Kemiskinan dan Ketidakmerataan di Indonesia (Suatu Analisis Awal). PT. Rineka Cipta. Jakarta.

Soekartawi. 1995. Pembangunan Pertanian. PT Raja Grafindo Persada. Jakarta

Analisis Ketimpangan Distribusi Pendapatan Petani Bawang Merah Dan Non Petani Bawang 161 Merah Di Desa Lam Manyang Kecamatan Peukan Bada Kabupaten Aceh (Medita Ivanni, Safrida, T. Makmur)

Jurnal Ilmiah Mahasiswa Pertanian Unsyiah, Vol. 2, No. 1, Februari 2017: 155-162 
Sukirno, S. 2002. Teori Mikro Ekonomi. Cetakan Keempat Belas. Rajawali Press. Jakarta

Suratiyah. 2006. Ilmu Usahatani. Penebar Swadaya. Jakarta.

Susanti, H. 1995. Indikator-Indikator Makro Ekonomi. LPFE - UI. Jakarta.

Todaro, M. P. 1999. Economics Development in the Third World, The Longman Inc New York.

2006. Pembangunan Ekonomi di Dunia Ketiga. Penerbit

Erlangga. Jakarta.

. 2013. Membangun Pertanian Dengan Pemberdayaan Masyarakat Tani Terobosan Menanggulangi Kemiskinan. Pustaka Baru Press. Yogyakarta.

. 2004. Makro Ekonomi. Raja Grafindo Persada. Jakarta.

2006. Ekonomi Pembangunan (Proses, Masalah, dan Dasar Kebijaksanaan). Fakultas Ekonomi UI. Jakarta.

2006. Analisis Usahatani. UI Press. Jakarta.

. 2012. Distribusi Pendapatan menurut Kriteria Bank Dunia dan Indeks Gini. Jakarta.

1999. Pengantar Perencanaan dan Pembangunan Ekonomi Daerah. BPFE.

Yogyakarta

2010. Ekonomi Pembangunan. Yogyakarta: UPP STIM YKPN. 